\title{
Observation of very large and steep internal waves of elevation near the Massachusetts coast
}

\author{
Alberto Scotti ${ }^{1}$ and Jesús Pineda ${ }^{2}$ \\ Received 20 July 2004; revised 14 September 2004; accepted 18 October 2004; published 25 November 2004.
}

[1] We report on near-bottom waves of elevation with amplitude nearly half the $25 \mathrm{~m}$ water column, very steep, and propagating into a sheared turbulent waveguide. The waves contained trapped cores transporting parcels of water shoreward. These large waves depart strongly from weakly-nonlinear and weakly-nonhydrostatic conditions and challenge established paradigms. They can also represent an important factor in the across-shore transport of plankton and contaminants. INDEX TERMS: 4544 Oceanography: Physical: Internal and inertial waves; 4219 Oceanography: General: Continental shelf processes; 4568 Oceanography: Physical: Turbulence, diffusion, and mixing processes; 4524 Oceanography: Physical: Fine structure and microstructure; 4815 Oceanography: Biological and Chemical: Ecosystems, structure and dynamics. Citation: Scotti, A., and J. Pineda (2004), Observation of very large and steep internal waves of elevation near the Massachusetts coast, Geophys. Res. Lett., 31, L22307, doi:10.1029/2004GL021052.

\section{Introduction}

[2] High-frequency nonlinear internal waves are widespread in shelf and coastal waters (C. Jackson, An atlas of internal solitary-like waves and their properties, 2nd ed., 2004, available at http://www.internalwaveatlas.com/ Atlas2 index.html). To date, most published studies deal with waves of depression riding on a shallow pycnocline, which often have a surface signature that can be easily recognized by remote sensing techniques (see, e.g., the collection of JOWIP and SARSEX papers in Journal of Geophysical Research, 93(C10), 1988). However, it is possible to have waves of elevation when the pycnocline is closer to the bottom than to the surface. Since this is often the case in shallow waters, we expect nonlinear internal waves of elevation in the near-shore to be common. The most studied generation mechanism for waves of elevation is the interaction of a nonlinear wave of depression propagating along a shoaling bottom. Within the weakly nonlinear long wave Korteweg-de Vries $(\mathrm{KdV})$ framework [Grimshaw, 1997; Grimshaw et al., 1998] waves of depression morph into waves of elevation near the point where the pycnocline is located halfway between the surface and the bottom [Grimshaw et al., 1999]. In recent years, improved in situ field observations have begun to expose the limitation of the KdV approach [Stanton and Ostrovsky, 1998].

\footnotetext{
${ }^{1}$ Department of Marine Sciences, University of North Carolina, Chapel Hill, North Carolina, USA.

${ }^{2}$ Biology Department, Woods Hole Oceanographic Institution, Woods Hole, Massachusetts, USA.
}

Copyright 2004 by the American Geophysical Union. 0094-8276/04/2004GL021052\$05.00
Moreover, waves of elevation in the near shore environment present additional challenges, such as enhanced bottom drag, shorter wavelengths and propagation in an environment that can be more energetic than farther offshore. A more realistic approach consists in numerically solving the Euler (or Navier-Stokes) equations along a vertical two-dimensional plane aligned along the direction of propagation [Vlasenko and Hutter, 2002; Lamb, 2004]. In these process-oriented studies, a shoaling wave of depression undergoes a strongly nonlinear evolution that results in a long wave of depression moving forward, which lowers the pycnocline, followed by a set of high-frequency nonlinear waves of elevation riding on the displaced pycnocline. These theoretical and numerical predictions are largely untested in the field, since observations of waves of elevations are scarce and so far have relied on models to supplement the lack of detailed measurements, creating a catch-22 situation [Klymak and Moum, 2003]. In this report, we take advantage of a recently developed technique [Scotti et al., 2004] to provide a high-resolution "radiography" (currents and density) of a set of waves of elevation observed in Massachusetts Bay just offshore of Scituate, MA (Figure 1). Since we do not appeal to a model to interpret or supplement our observations, and because of the complete characterization of the wave-guide ahead, these measurements can be used as a base for testing models under strongly nonlinear and turbulent conditions.

[3] Understanding of nonlinear waves in coastal waters has implications that go beyond physical oceanography. Gradients of many ecological and environmental variables are much steeper in the cross- than in the along-shore dimension [Mullin, 1993]. Thus, physical processes transporting fluid normal to the coastline can play a preponderant role in influencing coastal ecological patterns and the distribution of contaminants in many near-shore areas [Shanks, 1983; Pineda, 1991, 1999; Leichter et al., 2003; Bohem et al., 2002].

\section{Experiment}

[4] Nonlinear internal waves in Massachusetts Bay are well known [Halpern, 1971; Haury et al., 1979, 1983; Chereskin, 1983]. They are forced by the barotropic tide flowing over Stellwagen Bank (Figure 1), and propagate to the SW as waves of depression along the shallow seasonal thermocline.

[5] Previous observations focused on the deep section of the bay, west of Stellwagen Bank and east of the 40-m isobath. Analysis of satellite-borne Synthetic Aperture Radar (SAR) images [Trask and Briscoe, 1983] did not reveal any wave activity west of the 40-m isobath, and it was assumed that waves would shoal and dissipate before reaching the shallow reach of the bay. We decided to revisit 


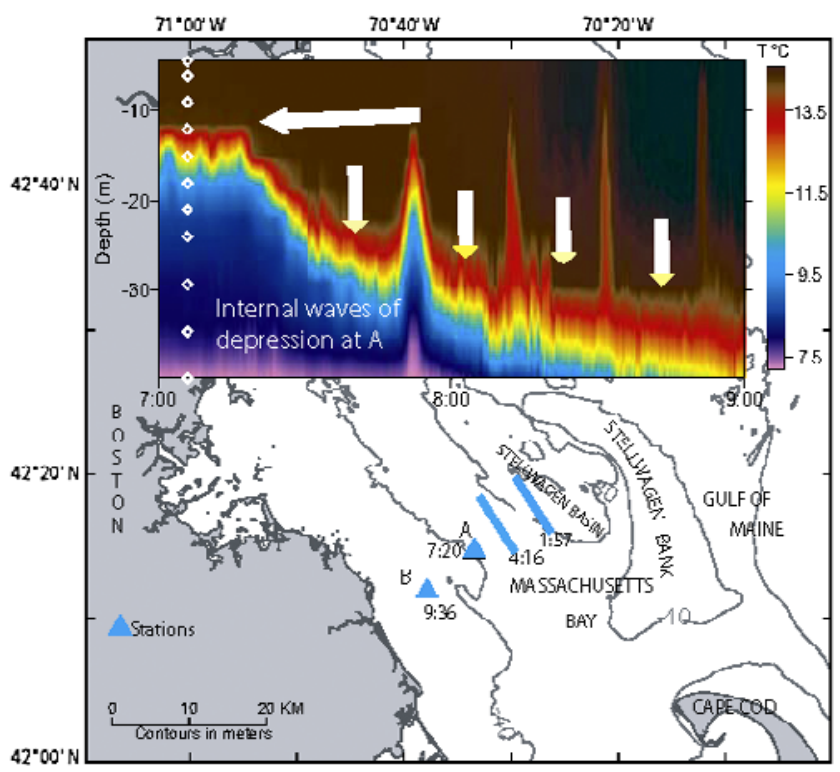

Figure 1. Massachusetts Bay and deployment sites. The ADCP was at $42^{\circ} 12.510^{\prime} \mathrm{N} ., 70^{\circ} 37.496^{\prime} \mathrm{W}$, and the temperature mooring at $42^{\circ} 12.506^{\prime} \mathrm{N}$., $70^{\circ} 37.591^{\prime} \mathrm{W}$. (B in the map). A second temperature mooring was deployed at $42^{\circ} 14.515^{\prime} \mathrm{N}$., $70^{\circ} 33.344^{\prime} \mathrm{W}$. (A). The thick lines in Stellwagen Basin show the successive location of a train of internal waves of depression propagating to the SW observed acoustically from on board of the R/V Connecticut. The time mark next to each symbol shows the arrival time for that station of the nonlinear internal waves. The inset shows the passage of 4 waves (vertical arrows) at A and the white diamonds show the thermistor position. Note how they are flattened, and the progressive lowering of the thermocline. The horizontal arrow points to the wave of depression moving forward.

this issue when we looked at data collected more recently on the western side of Stellwagen Basin (near site A, Figure 1) which showed that the shoaling nonlinear internal waves radiate a considerable amount of baroclinic energy to the west. Also, preliminary observations in $23 \mathrm{~m}$ of water (near B) in 1999 showed intense internal wave activity. A fully nonlinear and nonhydrostatic model showed that the 45-m isobath was a likely candidate for wave-bottom interaction. Thus, we deployed a mooring along the $25-\mathrm{m}$ isobath during the late summer of 2001 (Figure 1, site B), which revealed sets of high-frequency and short-wavelength internal waves of elevation propagating to the west. Currents were measured by a bottom mounted $1200 \mathrm{KHz}$ ADCP deployed in $25 \mathrm{~m}$ of water; the instrument sampled currents in 30 vertical bins, each $0.75 \mathrm{~m}$ thick, averaging over 30 pings (0.533 $\mathrm{s}$ each). Temperature data was collected every 8 s by 5 Seabird SBE39 thermistors deployed on a subsurface mooring $130 \mathrm{~m}$ to the west of the ADCP. Since the temperature-salinity relationship from nearby CTD casts followed a tight curve, temperature alone was sufficient to determine the density. The velocity field measured by the ADCP was used to infer the stratification just ahead of the waves based on the assumptions that (i) along streamlines the temperature remains constant and (ii) the shape of the frontal wave remains reasonably constant as it travels from the ADCP to the thermistor chain. The raw ADCP output was used to estimate the speed and direction of propagation of the waves [Scotti et al., 2004]. The measured propagation speed was used to represent the data in a frame of reference moving with the waves, which was essential to characterize the slope of the waves. The deployment covered 12 tidal periods. Very well developed sets of large-amplitude and high-frequency internal waves were observed during the latter part of two tidal cycles. A second temperature mooring was deployed further offshore (A in Figure 1) with 11 Seabird SBE39, at a depth of $45 \mathrm{~m}$. During the deployment period we also mapped acoustically the waves of depression propagating across Stellwagen Basin on board of the R/V Connecticut.

[6] In this report, we focus on a packet of waves with periods less than 5 minutes that passed by the mooring shortly after 1445 on 16 September 2001. Prior to the arrival of the waves the thermocline lowered progressively, remained within $5 \mathrm{~m}$ from the bottom for about 1 hour (maximum Brünt-Väisälä frequency $\mathrm{N}=0.075 \mathrm{~s}^{-1}$ ), and was quickly restored to its original location after the passage of the high-frequency waves (Figure 2). Just before the arrival of the waves, the flow was directed shoreward above the thermocline, while below it we observed a strong offshore return flow. The resulting shear was sufficiently intense to lower the local Richardson number $\mathrm{N}^{2} / \mathrm{S}^{2}$, where $\mathrm{S}$ is the shear, below the critical value for the onset of Kelvin-Helmholtz instabilities in a narrow region $18 \mathrm{~m}$ below the surface (Figure 2, bottom panel), implying high levels of turbulence ahead of the waves, which can explain the unusually large value of the acoustic backscatter measured by the ADCP between 18 and $23 \mathrm{~m}$ ahead of the waves (Figure 2, upper panel). Against this background, we observed a train of well defined high frequency internal waves propagating almost exactly westward at $21 \mathrm{~cm} / \mathrm{s}$. When observed in a frame of reference moving with the phase speed, the current and temperature data overlapped perfectly for the first two waves, providing an independent verification of our estimate of the speed of propagation. The overlap degraded progressively towards the trailing edge of the packet, suggesting that the train evolved on a relatively fast scale. The individual waves were very large, both in relation to the total depth, and with respect to the thickness of the layer initially below the thermocline. The slope of the isopycnal surfaces, assumed to coincide with the slope of the high backscatter layer, was large, about $20^{\circ}$. The first two waves contained a trapped core (Figure 2, bottom left panel).

\section{Discussion}

\subsection{Nonlinearity}

[7] To quantify the degree of nonlinearity and the departure from hydrostatic behavior, we consider the terms in the Bernoulli function $B=p^{\prime}+E_{p}+E_{k}$, where $E_{k}$ is the kinetic energy density, $E_{p}$ the Available Potential Energy (AEP) [Winters et al., 1995] and $p^{\prime}$ is the pressure anomaly due to the passage of the waves, the sum of the baroclinic pressure anomaly $p_{b c}=-\int_{0}^{z} g \rho^{\prime} d s$ and the pressure $p_{n h}$ induced by the vertical acceleration of water parcels. For linear hydrostatic waves $B \approx p_{b c}$, so that $R_{N L}=\left|E_{p} / p_{b c}\right|$ and $R_{D}=\left|p_{n h} / p_{b c}\right|$ can be interpreted as a measure of nonlinearity and deviation from hydrostatic behavior (i.e., dispersion) respectively. 


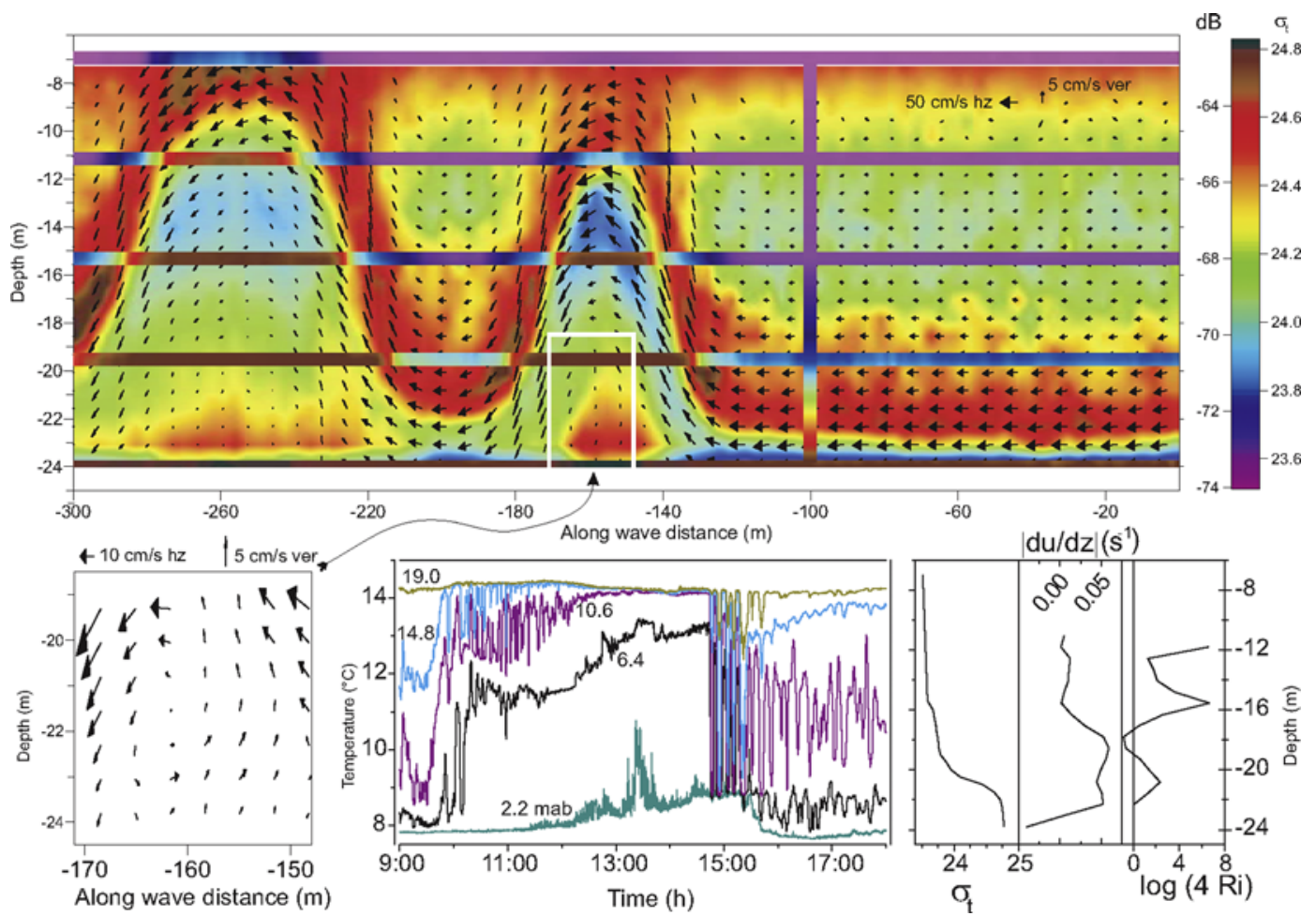

Figure 2. High-frequency internal waves of elevation on 16 September 2001 at A. Top panel. Range-corrected acoustic backscatter intensity from the Acoustic Doppler Current Profiler (background), density record at the depth of the five thermistors (horizontal bars), and current vectors. The time coordinate has been transformed into along-wave distance using the velocity of propagation and currents are shown in a frame of reference moving with the estimated wave speed. The vertical bar at $\mathrm{x}=-100 \mathrm{~m}$ shows the inferred density just ahead of the first wave. The high-backscatter area at the base of the waves marks the extent of the recirculation areas. The white box is magnified in the left bottom panel. Center bottom panel. Temperature record at depths in meters above the bottom over a period of 9 hours. Right bottom panel. Inferred density (left), magnitude of shear (center) and gradient Richardson number (right) just before the arrival of the first wave. Note the area of dynamic instability at $18 \mathrm{~m}$.

Both $R_{N L}$ and $R_{D}$ show large departure from zero during the passage of the waves, especially near the bottom, when the ratios are at times larger than 5 (Figure 3).

\subsection{Turbulence}

[8] The region of dynamic instability $\left(N^{2} / S^{2}<1 / 4\right)$ just above the thermocline in the wave-guide implies that the waves propagate in an environment where a significant level of turbulence is already present. Analysis of the variance of the beam velocities during the 20 minutes prior to the passage of the first wave [Lu and Lueck, 1999] shows a strong turbulent layer approximately $2-\mathrm{m}$ thick, centered $18 \mathrm{~m}$ below the surface, dissipating about $4 \times 10^{-3} \mathrm{~W} / \mathrm{m}^{3}$, a value considerably larger than ones encountered in standard oceanic conditions. [The main sources of error in the estimate of the Reynolds stress using the Lu and Lueck method are (i) unsteadiness in the pitch and roll of the instrument, (ii) Doppler noise and (iii) horizontal inhomogeneity of the turbulent quantities. During the period considered here, the rms fluctuations in pitch and roll were less than $0.06^{\circ}$, hence negligible. The measured Reynolds stress was one order of magnitude larger than the Doppler noise level, and the flow was found to be horizontally homogenous when averaged over 20 minutes.]

[9] The passage of the waves causes the shear acting along unstable streamlines to increase to up to twice the value found ahead (Figure 3), further lowering the local

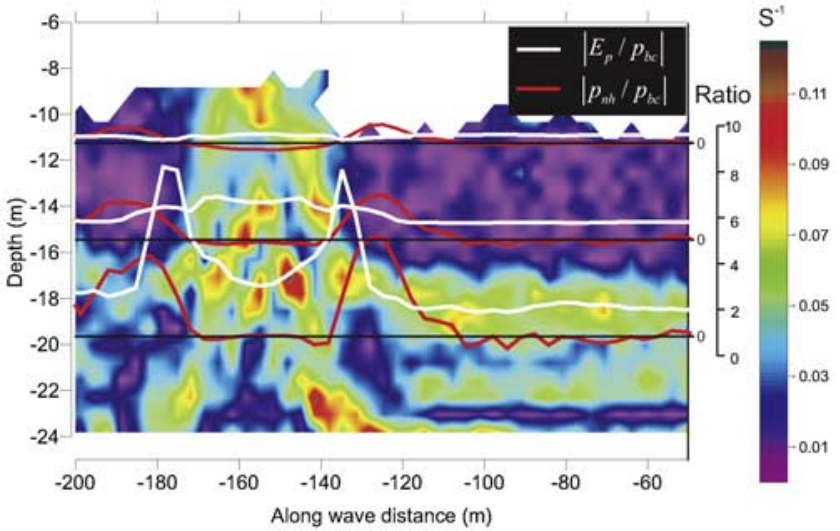

Figure 3. Local magnitude of the shear calculated from the current field. Note the high shear regions found on either side of the displaced thermocline. Red lines show the ratio $\mathrm{R}_{\mathrm{NL}}$ of APE to baroclinic pressure, an indication of deviation from linearity, and white lines the ratio $R_{D}$ of non hydrostatic pressure anomaly to baroclinic pressure anomaly at $-11.2,-15.4$ and $-19.6 \mathrm{~m}$; magnitudes are with respect to those depths. 
Richardson number. The increase in backscatter intensity observed towards the end of the packet is consistent with this hypothesis. It is difficult to quantify how turbulence evolves along these streamlines. Available experiments and numerical simulations of stratified turbulence subject to steady linear shear of magnitude $\mathrm{S}$ suggest that under unstable conditions turbulence will increase exponentially with an e-folding scale ranging from $0.1 / \mathrm{S}$ to $0.2 / \mathrm{S}$, depending on the Richardson number [Jacobitz et al., 1997]. In the present case, the equivalent horizontal e-folding distance could be as small as $10 \mathrm{~m}$ but no more than $30 \mathrm{~m}$, depending on the value of $\mathrm{S}$ used. For the sake of discussion, we assume that along the first two waves, the mean turbulent dissipation rate is twice the value found ahead, or $8 \times 10^{-3} \mathrm{~W} / \mathrm{m}^{3}$, which amounts to a total dissipation of $2.8 \mathrm{~W} / \mathrm{m}$ over the first two waves. This value is comparable to the value reported by Klymak and Moum [2003]. Unlike waves of depression propagating close to the surface, these waves have an additional source of energy dissipation, bottom friction. It can be estimated as $V_{p} \int_{0}^{L} \tau d x$ where $\tau$ is the turbulent stress at the base of the waves, L the length of the packet and $V_{p}$ is the propagation speed. The former can be estimated from the measured near-bottom currents using an appropriate drag coefficient [Thompson et al., 2004], noting that the bottom boundary layer is well mixed under the waves. For the present case, the dissipation over the first two waves totals $3.1 \mathrm{~W} / \mathrm{m}$. Thus, the energy dissipated by bottom friction is comparable to the one lost to internal turbulence production.

\subsection{Trapped Cores}

[10] Nonlinear waves with trapped cores have been observed in the lab [Manasseh et al., 1998] and predicted theoretically [Derzho and Grimshaw, 1997]. However, to the best of our knowledge, conclusive field evidence of the existence of trapped cores in waves of elevation has never been presented. For the present case, the evidence is based on the measured currents, backscatter and temperature. The forward velocity in the core exceeds $5 \mathrm{~cm} / \mathrm{s}$, above the error level of the ADCP and $25 \%$ of the propagation speed. The motion in the core is counterclockwise. This agrees with lab experiments and supports theoretical assumptions quoted above. Numerical experiments [Lamb, 2002] have produced waves with opposite circulation. It is likely that the circulation in the core is sensitive to the particular generation mechanism, as well as to the nature of the boundary condition (free slip vs. no-slip). The volume of the trapped core under the first wave is about $20 \mathrm{~m}^{3}$ per linear meter of wave, equivalent to a flux of $4.6 \times 10^{-4} \mathrm{~m}^{3} / \mathrm{s}$ per alongcrest linear meter over a tidal cycle. This feature is likely to have the most direct environmental impact as discussed below. The core in the second wave is not as well organized as the one in the leading wave.

\subsection{Generation}

[11] Acoustics observations made onboard of the $\mathrm{R} / \mathrm{V}$ Connecticut further east earlier during the day revealed a set of nonlinear waves of depression propagating to the WSW (thick lines in Figure 1). The waves were also recorded at A (Figure 1, inset). In Stellwagen Basin the waves had a sech ${ }^{2}$ shape, while at A the four waves shown (vertical arrows) were severely distorted by the interaction with the bottom wide flat troughs and steep trailing edges, in agreement with Vlasenko and Hutter's [2002] model (see, e.g., their Figure 9). We hypothesize that the wave of depression racing forward at A (horizontal arrow) is the same wave of depression that arrives at B around 0930, setting the stage for the development of the waves of elevation observed here. This scenario agrees with the simulations of Lamb [2004], but not with KdV theory [Grimshaw et al., 1999], according to which waves of depression should morph directly into waves of elevations.

\section{Conclusions}

[12] We have presented observations of a train of highly nonlinear waves of elevations propagating in shallow waters. The leading waves have well defined recirculating cores and propagate in an environment characterized by high shear and turbulence. The evolution of the density field before and during the passage of the wave is consistent with existing numerical simulations, suggesting that waves derive their energy from waves of depression impinging on a shoaling bottom further upstream. The waves have characteristics that make them unlikely candidates for a description based on weakly nonlinear theory.

[13] Many questions remain unanswered. The most interesting is how far inshore these waves will travel. From the location of the present study to the shore the bottom gently slopes upward, so it is conceivable that they will propagate until the stratification will allow it. Equally important is to assess their environmental impact. The conditions upstream of the waves (strong flow just above the sea bottom) and the strong convergence at the bottom favor sediment resuspension, including recently settled invertebrate larvae and toxic algae cysts. Settled larvae and toxic resting cysts could be injected rapidly to the water column. The existence of a trapped core makes these waves prime candidates for transporting material such as larvae of littoral species. Furthermore, nutrients are more abundant below the thermocline, and sewage is often discharged below thermocline, so these waves have potential for transporting larvae, nutrients and sewage onshore, as suggested for internal tidal surges in other locations [Pineda, 1991, 1999; Leichter et al., 2003; Bohem et al., 2002].

[14] Acknowledgments. We wish to thank J. Leichter, F. Tapia, S. Gallager, P. Alatalo and A. Kukulya for assistance with the data and the captain and crew of $\mathrm{R} / \mathrm{V}$ Connecticut for their help. K. Lamb, R. Beardsley, R. Camassa and two anonymous referees provided constructive criticism. Funding provided by ONR, grants N00014-01-1-0172 and N00014-03-1-0553.

\section{References}

Bohem, A. B., B. F. Sanders, and C. D. Winant (2002), Cross-shelf transport at Huntington Beach: Implications for the fate of sewage discharged through an offshore ocean outfall, Environ. Sci. Technol., 36, 1899-1906.

Chereskin, T. K. (1983), Generation of internal waves in Massachusetts Bay, J. Geophys. Res., 88, 2649-2661.

Derzho, O. G., and R. Grimshaw (1997), Solitary waves with a vortex core in a shallow layer of stratified fluid, Phys. Fluids, 9, 3378-3385.

Grimshaw, R. (1997), Internal solitary waves, in Advances in Coastal and Ocean Engineering, vol. 3, edited by P. L.-F. Liu, World Sci., River Edge, N. J.

Grimshaw, R., L. Ostrovsky, V. I. Srira, and Y. A. Stepanyants (1998), Long nonlinear surface and internal gravity waves in a rotating ocean, Surv. Geophys., 19, 289-338

Grimshaw, R., E. Pelinovsky, and T. Talipova (1999), Solitary wave transformation in a medium with sign-variable quadratic nonlinearity and cubic nonlinearity, Physica D, 132, 40-62. 
Halpern, D. (1971), Observation of short period internal waves in Massachusetts Bay, J. Mar. Res., 29, 116-132.

Haury, L. H., M. B. Briscoe, and M. H. Orr (1979), Tidally generated internal wave packets in Massachusetts Bay, Nature, 278, 312-317.

Haury, L. H., P. H. Wiebe, M. H. Orr, and M. G. Briscoe (1983), Tidally generated high frequency internal wave packets and their effects on plankton in Massachusetts Bay, J. Mar. Res., 41, 65-112.

Jacobitz, F. G., S. Sarkar, and C. W. Van Atta (1997), Direct numerical simulations of the turbulence evolution in a uniformly sheared and stably stratified flow, J. Fluid, 231-261.

Klymak, J. M., and J. N. Moum (2003), Internal solitary waves of elevation advancing on a shoaling shelf, Geophys. Res. Lett., 30(20), 2045, doi:10.1029/2003GL017706.

Lamb, K. G. (2002), A numerical investigation of solitary internal waves with trapped cores formed via shoaling, J. Fluid Mech., 451, 109-144.

Lamb, K. G. (2004), Large amplitude internal solitary waves: Properties and shoaling behavior, Eos Trans. AGU, 84(52), Ocean Sci. Meet. Suppl., Abstract OS22G-07.

Leichter, J. L., H. L. Stewart, and S. L. Miller (2003), Predicting highfrequency upwelling: Spatial and temporal patterns of temperature anomalies on a Florida coral reef, Cont. Shelf Res., 48, 1394-1407.

Lu, Y., and R. G. Lueck (1999), Using a broadband ADCP in a tidal channel. Part II: Turbulence, J. Atmos. Oceanic Technol., 16, 15681579 .

Manasseh, R., C.-Y. Chin, and H. J. Fernando (1998), The transition from density-driven to wave-dominated isolated flows, J. Fluid Mech., 361, $253-274$.

Mullin, M. M. (1993), Webs and Scales: Physical and Ecological Processes in Marine Fish Recruitment, Books Recruitment Fish. Oceanogr., Univ. of Washington Press, Seattle.

Pineda, J. (1991), Predictable upwelling and the shoreward transport of planktonic larvae by internal tidal bores, Science, 253, 548-551.
Pineda, J. (1999), Circulation and larval distribution in internal tidal bore warm fronts, Limnol. Oceanogr., 44, 1400-1414.

Scotti, A., B. Butman, R. C. Beardsley, P. Soupy-Alexander, and S. P. Anderson (2004), A modified beam-to-earth transformation to measure short-wavelength internal waves with an acoustic Doppler current profiler (ADCP), J. Atmos. Oceanic Technol., in press.

Shanks, A. L. (1983), Surface slicks associated with tidally forced internal waves may transport pelagic larvae of benthic invertebrates and fishes shoreward, Mar. Ecol. Prog. Ser., 13, 311-315.

Stanton, T. P., and L. A. Ostrovsky (1998), Observations of highly nonlinear internal solitons over the continental shelf, Geophys. Res. Lett., 25, $2695-2698$.

Thompson, C. E. L., C. L. Amos, N. Lecouturier, and T. E. R. Jones (2004), Flow deceleration as a method of determining drag coefficient over roughned flat beds, J. Geophys. Res., 109, C03001, doi:10.1029/ 2001JC001262.

Trask, R. P., and M. B. Briscoe (1983), Detection of Massachusetts Bay internal waves by synthetic aperture radar (SAR) on SEASAT, J. Geophys. Res., 88, 1789-1799.

Vlasenko, V., and K. Hutter (2002), Numerical experiments on the breaking of solitary internal waves over a slope-shelf topography, J. Phys. Oceanogr, 32, 1779-1793.

Winters, K. B., P. N. Lombard, J. J. Riley, and E. A. D'Asaro (1995), Available potential energy and mixing in density stratified fluids, J. Fluid Mech., 289, 115-128.

J. Pineda, Biology Department, Woods Hole Oceanographic Institution, Woods Hole, MA, USA.

A. Scotti, Department of Marine Sciences, University of North Carolina, 12-7 Venable Hall, CB \#3300, Chapel Hill, NC 27599-3300, USA. (ascotti@unc.edu) 